\title{
Interpretaciones sobre la violencia mexicana: alcances y límites
}

doi: http://dx.doi.org/10.32870/espiral.v22i63.1673.g1462 Miguel Ángel Vite Pérez*

En México, la violencia se convirtió en el tema central de la agenda gubernamental en el momento en que se decidió su criminalización, es decir, cuando se utilizó la fuerza armada para su combate, identificando al narcotráfico como la actividad ilegal principal que había causado distorsiones en el ejercicio estatal respecto a su función de seguridad pública; es decir, cuando se identificó que algunos agentes encargados de la seguridad pública, en el plano local y regional, habían desarrollado fuertes vínculos con los negocios ilícitos del narcotráfico.

Por tal motivo, la prioridad del gobierno federal, al menos en el sexenio presidencial de Felipe Calderón Hinojosa (2006-2012), fue la "recuperación" del control de la seguridad pública en los territorios que consideró que estaban en "manos" de las mafias de los estupefacientes, a través de la detención de los principales participantes del negocio ilegal y el castigo a sus aliados, que se desempeñaban en algún nivel de la autoridad y en los cuerpos policíacos.

Desde esta perspectiva, la violencia mexicana es vista como un problema de seguridad nacional, pero sin considerar que es un problema complejo que va más allá del ámbito

Nelson Arteaga Botello (coord.). (2013). Violencia en México. Actores, procesos y discursos. Madrid: Catarata. 
de policías y de la existencia de aliados como lo son las autoridades corruptas.

La violencia es parte de las relaciones sociales y se reproduce en contextos diversos, lo que permite analizarla desde un enfoque multidisciplinario, donde las conclusiones muestran que la violencia no necesariamente da como resultado la muerte o la desaparición de sus protagonistas directos o indirectos, sino que se ha transformado en un mecanismo de organización y desorganización de la vida pública y privada del país.

El miedo y el temor, considerados como dos resultados subjetivos de la violencia, en realidad han ayudado a generar una creencia colectiva de que la vida y el patrimonio personal están amenazados ante la incapacidad del Estado para controlar la expansión de las actividades ilícitas, que posteriormente se podrían convertir en criminales.

En este sentido, el libro coordinado por Arteaga Botello muestra el acierto de tener como eje temático la violencia en México y, al mismo tiempo, considerar algunas de sus manifestaciones a través de las diversas colaboraciones que lo integran, recuperando la idea de que la violencia no es un problema derivado del conflicto emanado de lo legal y lo ilegal, sino que se ha vuelto parte de la reproducción de las relaciones sociales, manifestadas a través de las creencias en la vida cotidiana (la cultura), las práctica sociales, las negociaciones y la necesidad o urgencia de vincular la vigilancia con el problema de la seguridad pública de parte del Estado y de algunos grupos sociales.

Por tal motivo, en la primera colaboración, escrita por la antropóloga Elena Azaola, se analiza la violencia de hoy como un hecho social que tiene fuertes lazos con las violencias de siempre, lo que obliga a preguntarse: ¿Cuáles son las violencias de siempre? La respuesta es la siguiente: las que no tienen como causa directa las actividades de la delincuencia organizada; sin embargo, son las violencias que

\section{8}


han sido toleradas e ignoradas, que en la coyuntura actual de combate al crimen organizado a causa del narcotráfico han contribuido al aumento de la violencia, junto con la descomposición de las instituciones de seguridad pública, además de las políticas económicas y sociales que no han disminuido la desigualdad social en el país (pp. 26-27).

En consecuencia, la autora relaciona las violencias toleradas e ignoradas, desde un punto de vista empírico, con el aumento de las tasas de homicidio por habitante, que en la década de los noventa del siglo Xx fueron más altas en México que las de los Estados Unidos, lo que proviene, según Azaola, de un aumento de la violencia en las familias y las instituciones; en otras palabras, la violencia que afecta a niños y niñas, jóvenes, mujeres, adultos mayores, el suicido, la violencia autoinfligida, lo sexual, conflictos de origen étnico, político y religioso, la pobreza, el hambre, la exclusión social (p.32).

Las violencias toleradas e ignoradas son violencias normales porque surgen todos los días en comparación con las violencias extraordinarias (visualizadas como patológicas), pero lo que está mostrando la autora es la existencia de una violencia estructural que se deriva de las insuficiencias de las políticas económicas y sociales, que en mayor o menor medida tienen manifestaciones particulares como las que enumera, es decir, violencia como agresión y como asesinato individualizado (p. 34).

La violencia "normal" presente en la sociedad mexicana debería de ser estudiada a través de sus manifestaciones particulares, lo que necesariamente llevaría al académico a no perder de vista que esta violencia es parte de las relaciones sociales y que en determinadas coyunturas es confundida con la violencia que promueve el Estado, cuando a través de sus políticas públicas se han criminalizado a los grupos que se dedican a lo ilegal, utilizando los métodos de la violencia directa como la muerte, la desaparición, la 
detención arbitraria, las falsas acusaciones, etcétera (véase Cretttiez, 2009).

De esta manera, se podría comprender por qué las políticas estatales de los últimos tres sexenios, que han buscado contener la violencia generada por el crimen organizado, en realidad la han exacerbado: en otras palabras, no se ha contenido la violencia, sino que ha aumentado. La respuesta es que han sido políticas de "combate", de "guerra", de "rendición incondicional" o de "exterminio" de los que la criminalización estatal ha clasificado como enemigos del orden social o de la llamada "paz pública" (véase Núñez Albarrán, 2012, pp. 42-43).

Lo que no está presente en el artículo de Elena Azaola es un análisis de las transformaciones que ha sufrido la institución de seguridad pública y de justicia a raíz de que el castigo a la ilegalidad ha justificado el surgimiento de nuevas maneras de criminalización de alguna parte del universo de las actividades ilegales, lo que ha incluido el uso de la violencia derivada de las fuerzas armadas estatales (Garland, 2007, pp. 62-63).

Por otro lado, en la segunda colaboración, el antropólogo Juan Luis Ramírez Torres estudia la violencia como un vacío de sentido que ha dado como resultado un culto generalizado entre algunos grupos sociales pobres hacia la Santa Muerte (pp. 61-96).

Esto ha sido posible porque la religiosidad popular ha combinado el credo cristiano con otras creencias místicas, sobre todo en coyunturas donde ha aparecido un sinsentido, un vacío de significado, que el individuo intenta cubrir a través del manto de la Santa Muerte (p. 62).

Lo interesante del tema es que el vacío es una manifestación de debilidad de los lazos sociales, en otras palabras, de la disolución de la solidaridad social, que condena al individuo al abandono al extinguirse el grupo, la comunidad, es decir, al perderse el sentido de pertenencia y hasta la identidad. 
De acuerdo con la anterior interpretación, Ramírez Torres establece que el culto a la Santa Muerte en realidad llena el vacío sin sentido dejado por los viejos sistemas simbólicos de creencias religiosas.

Sin embargo, ¿cuál sería la relación entre la violencia y el culto a la Santa Muerte? La posible respuesta es que la violencia ha destruido el sentido, ha creado un vacío semiótico que ha sido cubierto de manera parcial por medio de dicho culto. Sobre todo, que la violencia es leída como la causa de la disolución de los lazos sociales, creando una sensación de miedo e incertidumbre (p. 73).

Pero si existe una fealdad en el cuerpo cadavérico de la imagen, ¿cómo puede "llenar" un vacío existencial, es decir, construir un sentido entre los que practican su culto? El autor responde "[...] sobre cada despojo sobre la Tierra, regularmente brota la nueva vida. Sólo basta la belleza de la Esperanza" (p. 92). Al parecer todo radica en la interpretación que cada creyente pueda elaborar sobre un esqueleto sin carne, el cual puede ser cubierto por sus propios pensamientos y sentimientos, por el vestido o el adorno, lo que es una expresión de la búsqueda de su conversión en el lazo de unión entre creyentes para construir una nueva comunidad con nuevos horizontes y esperanzas (pp. 93-94).

En suma, el culto a la Santa Muerte no es una manifestación de la violencia, sino de la búsqueda de integración social, afectada por un entorno de destrucción de la seguridad institucional convertida en inseguridad pública (Vega Zayas, 2010, pp. 19-63).

El tercer artículo fue escrito por el antropólogo Salvador Maldonado Aranda (pp. 97-130) y la preocupación central que le permitió argumentar sobre la construcción de un orden particular, bajo el dominio del narcotráfico, fue la manera en que los miembros de una comunidad michoacana negocian la violencia. 
$\mathrm{Su}$ experiencia de campo le permitió reconstruir las nuevas prácticas sociales, que por ejemplo en la localidad rural El Capulín, localizada en el estado de Michoacán, surgieron a raíz de un orden social establecido por Los Caballeros Templarios y que fue tolerado y aceptado, aunque con algunas resistencias, lo que les permitió negociar la producción y consumo de drogas entre los miembros de la comunidad (pp. 97-100).

Lo que se debe destacar de esta contribución es el estudio de la violencia en el medio rural, sobre todo porque el autor considera que el narcotráfico es parte de la historia de formación de identidades regionales, pero en los límites del estado, donde se concentra el cultivo de droga vegetal y sintética (p. 101).

Por tanto, la lucha por el control del narcotráfico se vincula con la lucha política y las luchas agrarias, y con el mantenimiento de identidades y hasta con el control territorial. En este contexto, los cárteles de la droga en Michoacán han construido sus propios códigos. Por ejemplo, La Familia Michoacana fue un cártel que desafió el proyecto político y cultural del Estado, organizado con los poderes regionales institucionales, a través de un fanatismo religioso transmitido por medio de sus narcomensajes, reclutamiento y adiestramiento (p. 102).

Pero el desafío, según Maldonado Aranda, que ha representado para el Estado mexicano La Familia Michoacana, ha sido su legitimidad al velar por la seguridad y lograr desplazarlo de tareas de orden social como recaudación de cuotas, funciones de gobierno, etcétera (pp. 102-103).

La violencia del narcotráfico ha obligado a la población a construir estrategias para evitarla, tolerarla, negociarla o enfrentarla, lo que depende también del estrato socioeconómico, lugar de residencia y de los lazos de protección (p. 105).

Lo anterior significa una generalización de la violencia directa en las localidades rurales y de la costa michoacana, 
manifestada como un desplazamiento forzado de familias hacia las ciudades; sin embargo, según el autor, es un tipo de violencia no sólo generada por el narcotráfico sino por la fuerza armada del Estado (p. 109).

Por su parte, las clases media y alta han enfrentado la violencia directa a través de la movilidad residencial a otras urbes "[...] fenómeno conocido como desplazamiento forzado o interno" (p. 113). Este hecho tiene consecuencias porque se abandona y se pierde el patrimonio, que en el medio rural es la base de la reproducción de las familias, lo cual sería otra manera de empobrecimiento; sin embargo, para algunas familias es mejor conservar su patrimonio conviviendo con los grupos del narcotráfico, mientras que para otros sería mejor la opción del pago de cuotas para esquivar la extorsión y el secuestro (p. 116).

Finalmente, para las comunidades indígenas, como por ejemplo el pueblo de Cherán en la Meseta Tarasca de Michoacán, la violencia del narcotráfico y de la delincuencia en general ha sido histórica, sobre todo por la explotación mercantil de sus recursos forestales, lo que conlleva a la usurpación de sus terrenos comunales (pp. 116-117).

La violencia directa tiene como causa, según Maldonado Aranda, la violencia estructural derivada de la ausencia de políticas sociales y de desarrollo de parte del Estado para las poblaciones rurales, que favorecieron a partir de la década de los ochenta del siglo XX el cultivo y tráfico de droga en los poblados rurales del sur de Michoacán. En otras palabras, se ha transformado en causa del empobrecimiento de una parte de las clases medias, cuya opción para evitarlo ha sido dedicarse al "lavado" del dinero ilegal (p. 127).

En conclusión, existe un orden local articulado a las actividades legales e ilegales, lo que ha obligado a la población a negociar la violencia o a evadiarla mediante la movilidad residencial o la búsqueda de la protección del crimen organizado, lo que evidencia también que el Estado mexicano 
a través de sus instituciones actúa como los grupos criminales: despojando a las poblaciones rurales e indígenas de sus recursos (p. 128).

Esta contribución tiene como acierto la articulación de la violencia directa y la violencia estructural a través de una reconstrucción de las experiencias de algunos de los miembros de las diferentes comunidades rurales michoacanas cuando conviven con la violencia ejercida por los narcotraficantes y los aparatos de seguridad del Estado (Mastrogiovanni, 2014, p. 34).

Sin embargo, para el autor la violencia que sufre México ha sido provocada por el Estado y por el crimen organizado, dejando de lado los otros tipos de violencia; por tal motivo, es el Estado y su abandono social lo que ha provocado que los grupos criminales hayan impuesto su orden social en las localidades rurales, que son las que más han sufrido los efectos negativos de las políticas económicas neoliberales.

La cuarta contribución es de María Eugenia Suárez de Garay, que desde un punto de vista antropológico interpreta las violencias policiales en México (pp. 131-159).

Las policías mexicanas, según Suárez de Graray, han adquirido una importancia debido a un contexto caracterizado por la criminalidad y la inseguridad, acompañado de altos niveles de violencia e ilegalidad. Por ese motivo, los mandos militares ocupan las secretarías de seguridad pública de doce estados del país (p. 134).

En otras palabras, coroneles y capitanes realizan labores de vigilancia en municipios y ciudades donde se han agudizado las disputas violentas entre los cárteles de la droga.

La militarización de los mandos de seguridad pública es una consecuencia de la crisis de los cuerpos policíacos expresada como una falta de profesionalismo que garantice los derechos y las libertades de los ciudadanos. Esta falta de profesionalidad es resultado de un desorden institucional que ha favorecido la vulnerabilidad de los policías, llamada 
por la autora "subjetividad sojuzgada", donde la impunidad, el delito y la corrupción son parte de la debilidad de las instituciones encargadas de la seguridad pública (pp. 136-137).

El sistema policial mexicano ejerce un poder punitivo al margen de cualquier legalidad y control institucional. Su intervención es más reactiva y de choque; en otras palabras, genera un tipo de violencia institucional ilegal (p. 137).

Dichas aseveraciones obligan a preguntarse lo siguiente: ¿la violencia policial es consecuencia de un diseño institucional deficiente que se caracteriza por la ausencia de profesionalismo y que no ayuda a crear una nueva subjetividad policial? Para la autora sí. Se necesita, en consecuencia, un nuevo diseño institucional policial que ayude a transformar la función policial en una carrera institucionalizada, es decir, acorde con los ordenamientos legales (p. 139).

Sin embargo, la autora destaca que la profesionalización de la policía mexicana no significa depuración o purga policial porque la causa de la degradación policial se localiza en su decadencia institucional (p. 144).

En conclusión, la solución a la violencia policial pasa por la transformación de las instituciones policiales, lo que abarca cambios doctrinarios, adecuaciones culturales, cambios administrativos para que deje de lado el siguiente paradigma:

[...] de la seguridad pública que suele buscar la defensa del Estado, bajo la lógica del orden público, y la persecución del delincuente, adoptando el paradigma de la seguridad ciudadana que repone en el plano conceptual y práctico, el interés y las preocupaciones ciudadanas como referente sustancial para los estados [...] (p. 156).

Según mi punto de vista, el análisis muestra la urgencia de un cambio institucional en la fuerza policial porque la policía es quien tiene una relación directa con los hechos de violencia que afectan a los ciudadanos y a quien estos últi- 
mos responsabilizan de no actuar para detener las acciones violentas del crimen organizado.

La última colaboración es del sociólogo y coordinador del libro, Nelson Arteaga Botello, donde relaciona el tema de la vigilancia con la violencia. Sobre todo que la vigilancia considerada como control social, en las últimas décadas, se volvió rápidamente parte de los temas de seguridad pública por el uso de la tecnología como un mecanismo para vigilar los comportamientos sociales en los espacios públicos ante la amenaza real o ficticia de la violencia criminal, tecnología que posteriormente fue convertida en un peligro para la seguridad nacional (Bauman y Lyon, 2013, p. 7-16).

Sin embargo, Arteaga Botello subraya que la violencia en América Latina es parte de la configuración de los Estadosnación, que se mantiene como un componente esencial de las relaciones sociales porque existe un acceso de parte de los diferentes actores a los medios para producirla y dirigirla contra determinados objetivos (p. 162).

$\mathrm{El}$ autor también destaca que la vigilancia y la criminalidad en México se puede estudiar a través de tres sistemas de vigilancia: la ejercida por las organizaciones criminales, la desarrollada por las instituciones estatales encargadas de la seguridad pública, y por los grupos sociales organizados para garantizar su propia seguridad (pp. 163-164).

Dicha tipología recuerda la metodología de los tipos ideales diseñada por el sociólogo alemán Max Weber, pero más que eso, rescata su capacidad explicativa para comprender la relación entre vigilancia y violencia en México.

La violencia criminal tiene como causa la producción de drogas que se ubica como un asunto derivado de la crisis productiva del campo mexicano, donde las mafias han usado una red compleja de vigilancia que incluye desde censos de comercios hasta sistemas de videovigilancia (pp. 166-167).

Mientras, el Estado mexicano ha legalizado un sistema nacional de seguridad pública acompañado de una paulatina 
militarización en la misma que ha afectado el ejercicio de los derechos ciudadanos (p. 169).

Por su parte, la vigilancia social surge ante la urgencia de protección vecinal o comunal de un entorno peligroso, donde existe una violencia criminal que no ha podido ser erradicada a través de los medios institucionales; este tipo de vigilancia, sin embargo, reproduce la extralegalidad contra los que han sido considerados como criminales (p. 172).

En resumen, la vigilancia y la violencia criminal muestran una desorganización de los sistemas de seguridad nacional, lo que ha permitido el surgimiento de nuevas formas de violencia, que en el caso de la violencia social pueden transformar sus demandas de seguridad pública en demandas políticas y sociales que pueden acelerar el proceso de pérdida de legitimidad del Estado mexicano (p. 180).

Sin embargo, considero que la vigilancia estatal mexicana, al desplazarse hacia la seguridad pública, acelerada por la violencia criminal y social, no deja de lado su aspecto punitivo sino que tiende a buscar su profesionalización, olvidando que en un contexto de desigualdad social significaría el reforzamiento de su capacidad de criminalización para castigar a los que ha definido como enemigos del orden social y que se ubican en la amplia franja social de la ilegalidad, donde existe un acceso real a las oportunidades de vida para los pobres que les han sido negadas por las instituciones estatales. Esta consideración debería de ser tomada por el autor para que su análisis fuera más completo.

Bauman, Z. y Lyon, D. (20I3). Vigilancia líquida. Barcelona:

Bibliografía Paidós.

Crettiez, X. (2009). Las formas de la violencia. Buenos Aires: Waldhuter Editores. 
Bibliografía

Garland, D. (2007). Crimen y castigo en la modernidad tardía. Bogotá: Siglo del Hombre Editores-Universidad de los Andes-Pontificia Universidad Javeriana.

Mastrogiovanni, F. (20I4). Ni vivos ni muertos. La desaparición forzada en México como estrategia de terror. México: Grijalbo.

Núñez Albarrán, E. (2012). La tragedia del calderonismo. Crónica de un sexenio fallido. México: Grijalbo.

Vega Zayas,J.M.(20 I0). La seguridad pública en la era moderna y contemporánea. México:Universidad Autónoma Metropolitana Azcapotzalco. 